\title{
Os blocos de conteúdos dos Parâmetros Curriculares Nacionais: possi- bilidades através da Resolução de Problemas
}

\author{
The content blocks of the National Curriculum Parameters: possibilities through \\ Problem Solving
}

\author{
Fabiane Cristina Höpner Noguti ${ }^{* 1}$ e Andresa Maria Justulin ${ }^{2}$, \\ ${ }^{1}$ Professora da Universidade Federal do Pampa - Unipampa - Campus Alegrete, Brasil. \\ 2Professora da Rede Estadual de Ensino do Estado de São Paulo, Universidade Estadual Paulista "Júlio de Mesquita Filho" - \\ Unesp/RC- SP, Brasil.
}

\begin{abstract}
Resumo
Neste trabalho exploramos alguns problemas que abordam os blocos de conteúdos dos Parâmetros Curriculares Nacionais utilizando a Metodologia de Ensino-Aprendizagem-Avaliação de Matemática através da Resolução de Problemas. Para isso, apresentamos o roteiro, proposto por Onuchic e Allevato (2011), para os professores que pretendem trabalhar com a referida metodologia. Por meio de cinco problemas, que inicialmente foram trabalhados em minicursos e encontros com professores de Matemática, exploramos cada um dos blocos de conteúdo (Números e Operações; Espaço e Forma; Grandezas e Medidas e Tratamento da Informação). Ressaltamos que essa Metodologia exige uma nova postura do professor, que passa ser o mediador do processo de aprendizagem. Além disso, o problema torna-se o ponto de partida para o processo de construção de novo conhecimento, que ocorre enquanto os alunos resolvem o problema proposto. A formalização do conteúdo ou apresentação da teoria matemática deve ser a última etapa a ser realizada pelo professor. A avaliação, também adquire uma nova importância, ao se integrar ao processo de ensino para promover a aprendizagem.
\end{abstract}

Palavras-chave: Parâmetros Curriculares Nacionais. Resolução de Problemas. Ensino. Aprendizagem e Avaliação de Matemática. Metodologia de Ensino.

\begin{abstract}
In this paper we explore some problems that approach the content blocks of the National Curriculum Parameters using the Methodology of Teaching-Learning-Evaluation Mathematics through Problem Solving. For this, we present the roadmap proposed by Onuchic and Allevato (2011), for teachers who want to work with that methodology. Through five problems, which were initially worked in short courses and meetings with mathematics teachers, we explore each of the blocks of content (Numbers and Operations; Space and Shape; Quantities and Measurements and Data Processing). We emphasize that this methodology requires a new attitude from the teacher, turning out to be the mediator of the learning process. Furthermore, the problem becomes the starting point for the construction process of new knowledge, which occurs while the students solve the proposed problem. The formalization of the content or presentation of the mathematical theory should be the last step to be performed by the teacher. The evaluation also takes on a new importance, by integrating the teaching process to promote learning.
\end{abstract}

Keywords: National Curriculum Parameters. Problem Solving. Learning. Teaching and Evaluation in Mathematics. Teaching Methodology. 


\section{Introdução}

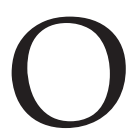

s Parâmetros Curriculares Nacionais (PCNs)

são os documentos que orientam os Ensinos Fundamental e Médio no Brasil e foram criados em consonância com a LDB - Lei de Diretrizes e Bases da Educação (BRASIL, 1996, no. 9.394/96).

O primeiro dos PCNs, publicado no ano de 1997, foi direcionado ao primeiro e segundo ciclos do Ensino Fundamental - atualmente do $1^{\underline{0}}$ ao $5^{\underline{0}}$ ano. Em 1998, foram apresentados os PCN para o terceiro e quarto ciclos do Ensino Fundamental - atualmente do $6^{\circ}$ ao $9^{\circ}$ ano. Os PCN para o Ensino Médio foram apresentados no ano de 2000.

Os PCNs não surgiram com o intuito de fornecer um currículo para cada uma das áreas de ensino e, sim, como uma orientação para as escolas na elaboração do seu programa curricular.

Os Parâmetros Curriculares Nacionais, referenciais para a renovação e reelaboração da proposta curricular, reforçam a importância de que cada escola formule seu projeto educacional, compartilhado por toda a equipe, para que a melhoria da qualidade da educação resulte da corresponsabilidade entre todos os educadores. A forma mais eficaz de elaboração e desenvolvimento de projetos educacionais envolve o debate em grupo e no local de trabalho (BRASIL, 1998, p. 9).

De acordo com essas orientações, os conteúdos de Matemática para o Ensino Fundamental estão organizados em quatro blocos: Números e operações, Espaço e forma, Grandezas e medidas e Tratamento da informação; e os conteúdos de Matemática para o Ensino Médio, também estão organizados em quatro blocos: Números e operações; Funções; Geometria; e Análise de dados e probabilidade.

Em relação ao trabalho com Resolução de Problemas em sala de aula, objeto desse estudo, os PCNs recomendam que o professor incentive não apenas a busca pela resposta correta, mas a construção dos conceitos matemáticos envolvidos no problema. Muito embora os professores utilizem os PCNs para orientar seu trabalho, entende-se que não são apresentadas formas de aplicar, em sala de aula, o conhecimento neles proposto, visto que, são fornecidas, nesse documento, apenas algumas orientações gerais para a exploração da resolução de problemas, a história da Matemática, o recurso aos jogos e o uso da tecnologia.

Desta forma, muitas vezes os professores não utilizam, nas suas práticas docentes, as metodologias de ensino recomendadas por não conhecerem materiais didáticos que as divulguem e as apresentem de uma maneira prática.

Para isso, neste artigo, propomos alguns problemas que exploram cada um dos quatro blocos dos PCNs referidos anteriormente, no intuito de indicar um possível caminho, ao professor, no trabalho com a Metodologia Ensino-Aprendizagem-Avaliação de Matemática através da Resolução de Problemas.

Em cada problema, apresentamos os objetivos a serem alcançados e comentários ao professor, considerando-se que o ambiente de sala de aula é muito rico e que, outras formas de trabalhar os mesmos problemas, podem acontecer. Ressaltamos, ainda, que os problemas apresentados foram previamente trabalhados com professores em minicursos e encontros da área de Educação Matemática.

Os problemas geradores foram escolhidos pensando em desenvolver conteúdos específicos relacionados a cada um dos blocos de conteúdos dos PCNs. Tais problemas foram retirados dos trabalhos de tese das autoras (NOGUTI, 2014; JUSTULIN, 2014), que haviam sido aplicados, em suas coletas de dados, junto a professores da Educação Básica, alunos de Licenciatura e/ ou ingressantes no Ensino Superior.

\section{A Metodologia de Ensino-Aprendizagem-Avalia- ção de Matemática através da Resolução de Proble- mas}

A Metodologia de Ensino-Aprendizagem-Avaliação de Matemática através da Resolução de Problemas propõe algumas atividades a serem desenvolvidas pelo professor, em sala de aula, para que ele possa explorar problemas com seus alunos em direção a construção de novos conceitos e conteúdos matemáticos. Além disso, essa Metodologia utiliza fortemente o trabalho em grupos e as discussões em sala de aula para a construção do conhecimento. Nesse processo, o professor faz o papel de mediador e condutor, enquanto os alunos assumem o papel de coconstrutores de seu conhecimento.

Nesse contexto, Onuchic (1999) define que "problema é tudo aquilo que não sabemos fazer, mas que estamos interessados em resolver" (p. 15).

Para ensinar através da Resolução de Problemas o professor utiliza um problema como ponto de partida e como meio para ensinar matemática. Nesse caso, temos a resolução de problemas como uma metodologia de ensino. Nessa abordagem o objetivo primeiro é apresentar, para os alunos, problemas que gerarão novos conceitos ou conteúdos. Segundo Nunes (2010, p. 85),

[...] a expressão "através de" é uma forma de ensinar e, consequentemente, aprender e, durante o processo, fazer matemática, pois o aluno diante do problema deve se mostrar como um coconstrutor do seu próprio conhecimento.

Sendo assim, os professores são facilitadores do processo e devem fazer conexões da matemática a ser construída com outras áreas da própria Matemática ou com outras áreas do conhecimento, possibilitando aos 
alunos estabelecerem novos conceitos. O ensino passa a ser centrado no aluno e a avaliação é integrada ao ensino, promovendo a aprendizagem.

A avaliação, dentro desta Metodologia, ocorre em todas as etapas do roteiro proposto, visto que, os alunos, além de serem avaliados pelo professor, também são agentes na avaliação de seus pares e na sua própria avaliação. É possível que o professor faça uso de avaliações escritas, porém a avaliação qualitativa é, com certeza, a forma mais indicada, quando o professor poderá observar mais atentamente, no trabalho dos grupos, o ganho de aprendizagem de cada aluno.

A avaliação ocorre na resolução do problema, na discussão nos grupos, na resolução do problema na lousa - em que os alunos devem apresentar suas soluções aos demais grupos - e, na plenária, momento em que as dúvidas dos alunos geram novas formas de pensar e repensar o problema.

Essa Metodologia é estudada e divulgada pelo GTERP - Grupo de Trabalho e Estudos em Resolução de Problemas, vinculado ao Programa de Pós-Graduação da Unesp - Rio Claro/SP, que tem obtido bons resultados em suas aplicações em teses e dissertações. Trabalhos relevantes publicados sobre este tema, além das teses e dissertações, estão no artigo de Onuchic e Allevato (2011) e nos capítulos do livro "Resolução de Problemas - Teoria e Prática" (ONUCHIC et al, 2014).

A partir desses trabalhos desenvolvidos, foi possível fundamentar a Metodologia de Ensino-Aprendizagem -Avaliação de Matemática através da Resolução de Problemas:

Ao considerar o ensino-aprendizagem-avaliação, isto é, ao ter em mente um trabalho em que estes três elementos ocorrem simultaneamente, pretende-se que, enquanto o professor ensina, o aluno, como um participante ativo, aprenda, e que a avaliação se realize por ambos. O aluno analisa seus próprios métodos e soluções obtidas para os problemas, visando sempre à construção de conhecimento. Essa forma de trabalho do aluno é consequência de seu pensar matemático, levando-o a elaborar justificativas e a dar sentido ao que faz. De outro lado, o professor avalia o que está ocorrendo e os resultados do processo, com vistas a reorientar as práticas de sala de aula, quando necessário. Chamamos a esse processo de trabalho de uma forma Pós'-Polya de ver a resolução de problemas. (ONUCHIC; ALLEVATO, 2011, p. 81)

Essa Metodologia possibilita ligar os conhecimentos

\footnotetext{
1 George Polya apresenta, no livro How to solve it: a new aspect of mathematical method (1945), quatro passos para um bom resolvedor de problemas matemáticos: 1) compreender o problema; 2) estabelecer um plano; 3) executar o plano; e 4) examinar a solução obtida. Nos estudos de Polya a ênfase estava nas heurísticas utilizadas na resolução de problemas, enquanto na abordagem como Metodologia de ensino, a ênfase está na construção dos conteúdos matemáticos que se dá enquanto o aluno resolve problemas.
}

prévios dos alunos à solução procurada para o problema e aos novos conhecimentos a serem construídos através da sua resolução. Ocorre uma investigação do padrão e da ordem, que são características da Matemática. Ao investigar, é possível que os alunos se utilizem de desenhos, jogos, tecnologia, esquemas, tabelas, gráficos, entre outros recursos, o que torna essa Metodologia bastante abrangente.

Onuchic e Allevato (2011, p. 83) apresentam uma sugestão de roteiro para a implementação em sala de aula da Metodologia de Ensino-Aprendizagem-Avaliação de Matemática através da Resolução de Problemas. Este roteiro tem por finalidade ajudar professores e alunos na organização de uma aula nesta Metodologia:

Preparação do problema - Selecionar um problema visando à construção de um novo conceito, princípio ou procedimento. Esse problema será chamado problema gerador. É bom ressaltar que o conteúdo matemático necessário para a resolução do problema não tenha ainda, sido trabalhado em sala de aula.

1) Leitura individual - Entregar uma cópia do problema para cada aluno e solicitar que seja feita sua leitura.

2) Leitura em conjunto - Formar grupos e solicitar nova leitura do problema, agora nos grupos.

1. Se houver dificuldade na leitura do texto, o próprio professor pode auxiliar os alunos, lendo o problema.

2. Se houver, no texto do problema, palavras desconhecidas para os alunos, surge um problema secundário. Busca-se uma forma de poder esclarecer as dúvidas e, se necessário, pode-se, com os alunos, consultar um dicionário.

3) Resolução do problema - A partir do entendimento do problema, sem dúvidas quanto ao enunciado, os alunos em seus grupos, em um trabalho cooperativo e colaborativo, buscam resolvê-lo. Considerando os alunos como coconstrutores da matemática nova que se quer abordar, o problema gerador é aquele que, ao longo de sua resolução, conduzirá os alunos para a construção do conteúdo planejado pelo professor para aquela aula.

4) Observar e incentivar - Nessa etapa, o professor não tem mais o papel de transmissor do conhecimento. Enquanto os alunos, em grupo, buscam resolver o problema, o professor observa, analisa o comportamento dos alunos e estimula o trabalho colaborativo. Ainda, o professor como mediador leva os alunos a 
pensar, dando-lhes tempo e incentivando a troca de ideias entre eles.

3. O professor incentiva os alunos a utilizarem seus conhecimentos prévios e técnicas operatórias, já conhecidas, necessárias à resolução do problema proposto. Estimula-os a escolher diferentes caminhos (métodos) a partir dos próprios recursos de que dispõem. Entretanto, é necessário que o professor atenda aos alunos em suas dificuldades, colocando-se como interventor e questionador. Acompanha suas explorações e ajuda-os, quando necessário, a resolver problemas secundários que podem surgir no decurso da resolução: notação; passagem da linguagem vernácula para a linguagem matemática; conceitos relacionados e técnicas operatórias; a fim de possibilitar a continuação do trabalho.

5) Registro das resoluções na lousa - Representantes dos grupos são convidados a registrar, na lousa, suas resoluções. Resoluções certas, erradas ou feitas por diferentes processos devem ser apresentadas para que todos os alunos as analisem e discutam.

6) Plenária - Para esta etapa são convidados todos os alunos, a fim de discutirem as diferentes resoluções registradas na lousa pelos colegas, para defenderem seus pontos de vista e esclarecerem suas dúvidas. O professor se coloca como guia e mediador das discussões, incentivando a participação ativa e efetiva de todos os alunos. Este é um momento bastante rico para a aprendizagem.

7) Busca do consenso - Depois de sanadas as dúvidas, e analisadas as resoluções e soluções obtidas para o problema, o professor tenta, com toda a classe, chegar a um consenso sobre o resultado correto.

8) Formalização do conteúdo - Neste momento, denominado formalização, o professor registra na lousa uma apresentação formal - organizada e estruturada em linguagem matemática padronizando os conceitos, os princípios e os procedimentos construídos através da resolução do problema, destacando as diferentes técnicas operatórias e as demonstrações das propriedades qualificadas sobre o assunto.

Cabe salientar que o trabalho com essa Metodologia pressupõe que o professor utilize e estimule o trabalho colaborativo e cooperativo entre os alunos. Para isso, ao iniciar uma aula nessa Metodologia o professor deve organizar os alunos em grupos de trabalho.

\section{Os Problemas sugeridos e alguns encaminha- mentos para o trabalho em sala de aula}

Apresentamos a seguir problemas que abordam os quatro blocos de conteúdos dos PCNs, nos quais faremos uso da Metodologia de Ensino-Aprendizagem-Avaliação de Matemática através da Resolução de Problemas, considerando as etapas do roteiro elaborado para auxiliar os professores em sala de aula. Apenas para o bloco de Números e Operações apresentamos dois problemas, pois consideramos que a Aritmética e a Álgebra são fortes padrões de conteúdos a serem trabalhados e são apresentados pelos PCNs em um único bloco.

Os problemas propostos apresentados podem ser trabalhados durante uma ou duas aulas de Matemática. O professor poderá, ao longo do trabalho com esta Metodologia, fazer uma previsão mais confiável do tempo necessário, considerando peculiaridades de cada turma. A princípio, por experiências já realizadas, é possível que em uma hora de aula seja possível resolver apenas um problema. Cabe ao professor, ao escolher o problema gerador, determinar quais conteúdos irá trabalhar a partir do mesmo. Sendo assim, é importante que o professor, ao selecionar os problemas, planeje seu nível de dificuldade para que eles não sejam difíceis, nem fáceis demais, mas adequados à série/ano e alinhados aos objetivos da aula, favorecendo os processos de ensino e aprendizagem programados pelo professor.

\section{Problema 1 - Aritmética}

(Krulick e Rudnick, 2005, p. 34) Ivete decidiu dar a maior parte de sua coleção de livros de bolso. Sua coleção é composta de menos de 100 livros. Ela está planejando dar a metade da coleção para o hospital e, em seguida, manter seus 10 livros favoritos. Ela vai dividir os livros restantes igualmente entre quatro amigos. Quantos livros podem estar na coleção de Ivete? Encontre todas as respostas possíveis.

Este problema é recomendado para ser trabalhado a partir do $5^{\mathrm{o}}$ ano do Ensino Fundamental, quando se deseja abordar conceitos da Aritmética, e a partir do $7^{\circ}$ ano explorando conceitos algébricos.

Pensando na Aritmética, pode ser trabalhado pelo professor, com seus alunos, buscando discutir os conceitos de divisibilidade e padrão. Através dele, o professor poderá também investigar os conhecimentos prévios dos alunos a respeito das operações fundamentais com os números naturais.

O professor deverá deixar claro aos alunos que para a resolução de um problema, podem ser apresentadas diferentes resoluções e estratégias.

De acordo com os resultados analisados em Noguti (2014), os alunos costumam iniciar esse problema, de 
forma mais simples, apresentando uma tabela de valores que descreva as condições dadas. É possível que eles iniciem o processo de esboço da tabela por um número qualquer (90), menor do que 100 e, a partir desse resultado, percebam que existem alguns padrões a serem seguidos na distribuição dos livros de acordo com o enunciado do problema. Por exemplo:

Tabela 1 - Divisão dos livros de Ivete

\begin{tabular}{|c|c|c|c|}
\hline $\begin{array}{l}\mathrm{N} \text { ú m e ro } \\
\text { de Livros }\end{array}$ & $\begin{array}{l}\text { Doados ao } \\
\text { Hospital }\end{array}$ & $\begin{array}{l}\text { Li v ros } \\
\text { da Ivete }\end{array}$ & $\begin{array}{l}\text { Livros para } \\
4 \text { amigos }\end{array}$ \\
\hline 90 & 45 & 10 & $35^{*}$ \\
\hline 28 & 14 & 10 & 4 \\
\hline 32 & 16 & 10 & $6^{*}$ \\
\hline 36 & 18 & 10 & 8 \\
\hline 40 & 20 & 10 & $10^{*}$ \\
\hline 44 & 22 & 10 & 12 \\
\hline 48 & 24 & 10 & $14^{*}$ \\
\hline 52 & 26 & 10 & 16 \\
\hline 56 & 28 & 10 & $18^{*}$ \\
\hline 60 & 30 & 10 & 20 \\
\hline 64 & 32 & 10 & $22^{*}$ \\
\hline 68 & 34 & 10 & 24 \\
\hline 72 & 36 & 10 & $26^{*}$ \\
\hline 76 & 38 & 10 & 28 \\
\hline 80 & 40 & 10 & $30^{*}$ \\
\hline 84 & 42 & 10 & 32 \\
\hline 88 & 44 & 10 & $34^{*}$ \\
\hline 92 & 46 & 10 & 36 \\
\hline 96 & 48 & 10 & $38^{*}$ \\
\hline
\end{tabular}

A partir desse passo, o professor poderá questionar os alunos sobre quais valores satisfazem o problema e, também, construir ou reconstruir conceitos importantes de números e operações, abordando os múltiplos e divisores de números naturais.

Como os alunos devem participar ativamente da construção de seu conhecimento, o professor poderá instigá-los com perguntas que os levem a pensar sobre o problema e a obter conjecturas a esse respeito: "Existe um padrão nas respostas que encontramos?"; "Todos os múltiplos satisfazem o problema?"; "O total de livros a ser distribuído por Ivete deve ser múltiplo ou divisor de que (ais) número(s)?".

O professor, a partir do $7^{\circ}$ ano, poderá sugerir a álgebra como ferramenta para resolver o problema:

Seja $l$ o número de livros de Ivete. Então, $\frac{l}{2}$ é o total de livros doado ao hospital e como Ivete reteve para si 10 livros, $\frac{l}{2}-10$ é o restante de livros a serem distribuídos para os 4 amigos. Assim,

$$
\frac{\frac{l}{2}-10}{4}=x
$$

Onde $x$ é o número de livros que cada amigo deverá receber. De (1), temos que:

$$
\frac{\frac{l-20}{2}}{4}=x \rightarrow \frac{l-20}{2}=4 x \rightarrow l-20=8 x
$$

Ou seja, que $l-20$ tem que ser divisível por 8 . A partir de (2) o aluno deve considerar todos os múltiplos de 8 para obter todos os valores possíveis de livros que

$$
\begin{array}{cc}
l-20=8 & \rightarrow l=28 \\
l-20=16 & \rightarrow l=36 \\
l-20=24 & \rightarrow l=44 \\
\cdot & \cdot \\
\cdot & \cdot \\
l-20=72 & \rightarrow l=92
\end{array}
$$

Ivete deve ter.

Os alunos devem ser levados a perceber que, nesse problema, estão trabalhando com a matemática discreta, já que o conjunto de dados é finito.

O professor poderá ainda, estender o problema para o Ensino Médio fazendo uso das Progressões Aritméticas.

\section{Problema 2 - Álgebra}

(Tinoco, 2011, p. 56) Dona Solange fabrica bombons caseiros e os vende em caixas decoradas. Em cada caixa ela coloca 6 bombons e as vende por $\mathrm{R} \$ 4,00$. Complete as tabelas a seguir.

Tabela 2 - Número de caixas e bombons

\begin{tabular}{|c|l|}
\hline Número de caixas & Número total de bombons \\
\hline 1 & \\
\hline 7 & \\
\hline 12 & \\
\hline 30 & \\
\hline
\end{tabular}

Tabela 3 - Caixas vendidas e quantia recebida

\begin{tabular}{|c|l|}
\hline $\begin{array}{l}\text { Número de caixas } \\
\text { vendidas }\end{array}$ & $\begin{array}{l}\text { Quantia recebida com a } \\
\text { venda }\end{array}$ \\
\hline 1 & \\
\hline 6 & \\
\hline 20 & \\
\hline 50 & \\
\hline
\end{tabular}


a) Qual a relação que existe entre o número de caixas e o de bombons nelas contidos?

b) Escreva uma igualdade que represente essa relação.

c) Qual a expressão que representa a quantia recebida por D. Solange pela venda de um número qualquer de caixas de bombons?

Este problema é recomendado para ser trabalhado a partir do $8^{\circ}$ ano do Ensino Fundamental, mas pode ser explorado também no Ensino Médio de acordo com os objetivos do professor.

Ao fazer uso da Metodologia de Ensino-Aprendizagem-Avaliação de Matemática através da Resolução de Problemas, o professor deve apresentar o problema aos alunos e em seguida, dividir a turma em grupos para trabalhá-lo. Os alunos podem, muitas vezes, apresentar dificuldade em trabalhar em grupo e o professor deverá auxiliá-los, incentivando-os a buscar a solução para o problema, em conjunto.

O professor poderá fazer algumas perguntas para ajudar os grupos a compreenderem o problema, como por exemplo: "Quantos bombons são colocados em uma caixa?"; "Faria sentido Dona Solange fazer 32 bombons? Por quê?".

Após cada grupo ter encontrado sua resposta para o problema, o professor deverá eleger um representante de cada grupo para apresentar a resposta obtida para a classe.

No item $a$ espera-se que os alunos respondam, ainda que verbalmente, que uma caixa comporta seis bombons. O professor poderia chamar atenção dos alunos para a razão:

$$
\frac{\text { caixa }}{\text { número de bombons }}=\frac{1}{6}
$$

Para responder o item $b$, os alunos poderiam escrever que:

, onde é o número de bombons e é o número de caixas.

É importante que o professor discuta, com os alunos, a ideia de variável dependente e de variável independente. Neste problema, o número de caixas é a variável independente e o número de bombons é a variável dependente. Nesse caso, não faria sentido que Dona Solange fizesse 32 bombons, por exemplo, pois sobrariam dois bombons.

No item $c$, os alunos deveriam responder que: $4,00 . N c$, onde é a quantia recebida pela venda e Nc é o número de caixas vendidas.

Destacamos aqui que os alunos poderiam utilizar outras variáveis como $x$ e $y$ para representar as expressões, desde que descrevessem seus significados.
Voltando ao uso da Metodologia apresentada, cabe ao professor, no momento da plenária discutir as resoluções propostas pelos grupos e formalizar os conteúdos matemáticos trabalhados. No caso desse problema seriam: a ideia de variável dependente e variável independente e a lei de uma função.

\section{Problema 3- Espaço e Forma}

(NCTM,1998 - Novembro) Abaixo temos um retângulo que foi dividido em 11 quadrados de diferentes tamanhos. $\mathrm{O}$ menor quadrado mede $9 \mathrm{~cm} \times 9 \mathrm{~cm}$. Encontre as dimensões dos lados do retângulo.

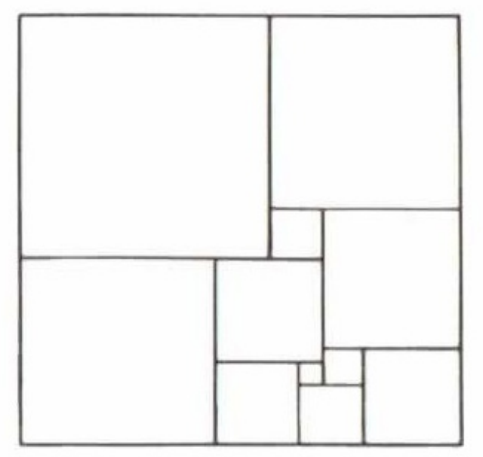

Figura 1 - Figura inicial do problema

Este problema pode ser trabalhado pelo professor, com seus alunos, buscando discutir o conceito de variável e das definições de quadrados e retângulos.

Não se espera que o professor inicie o trabalho com variáveis a partir desse problema, e sim, que ele seja utilizado quando os alunos compreendam o conceito de variável e possam perceber a sua necessidade para obter uma resolução nesse caso.

Os alunos, divididos em grupos, devem buscar padrões para resolver o problema. Para que a atividade seja proveitosa, o professor deve acompanhar o trabalho dos alunos desde o início. Esse problema exige que os alunos compreendam que, a partir do valor dado para o lado de um quadrado, o menor deles, deve-se estabelecer relações com os quadrados que estão ao seu redor.

Como se espera que o aluno participe ativamente da construção de seu conhecimento, o professor poderá instigá-lo com perguntas que o levem a pensar sobre o problema e, na medida do possível, quando perguntado, o professor deve responder ao aluno com uma nova pergunta que possa fazê-lo pensar sobre o problema. Se houver um impasse, ou seja, se o professor perceber que os alunos não estão conseguindo avançar na resolução do problema, o professor poderá então, auxiliá-los utilizando um problema secundário que possa ajudá-los a compreender o problema proposto.

No caso deste problema, o professor poderá perguntar 
aos alunos como a partir do primeiro quadrado pode-se encontrar valores para os demais. Algumas perguntas podem auxiliar o professor nesse processo: "Conhecemos o valor de um dos lados?"; "A partir do lado conhecido é possível obter o lado de outro quadrado?"; "Esse lado será numérico ou há a necessidade de se usar uma variável?"; "O que é uma variável?"; "É necessário, nesse problema, utilizar mais de uma variável?".

O professor deverá lembrar aos alunos que a figura é, na verdade, um retângulo formado por 11 quadrados, e que, portanto, ao determinar os lados da figura (retângulo), eles serão iguais dois a dois.

Finalmente, é possível obter o valor da variável utilizada (em nosso caso, $x$ ) e determinar além dos lados do retângulo, os lados dos quadrados internos.

Como problema complementar, o professor poderá propor que os alunos determinem a área de cada quadrado interno e, também do retângulo e obtenham relações entre elas.

Atribuindo o valor de para o lado do quadrado a direita do quadrado de lado, inicia-se o processo de descoberta dos lados dos quadrados internos, assim, o quadrado abaixo dos de lado e x terá medida . Conhecendo esses lados, encontra-se que o quadrado a direita terá medida

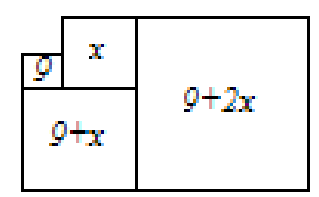

Figura 2 - Encontrando os quadrados iniciais

Seguindo o mesmo raciocínio, é possível obter os demais lados dos quadrados internos, como na figura a seguir:

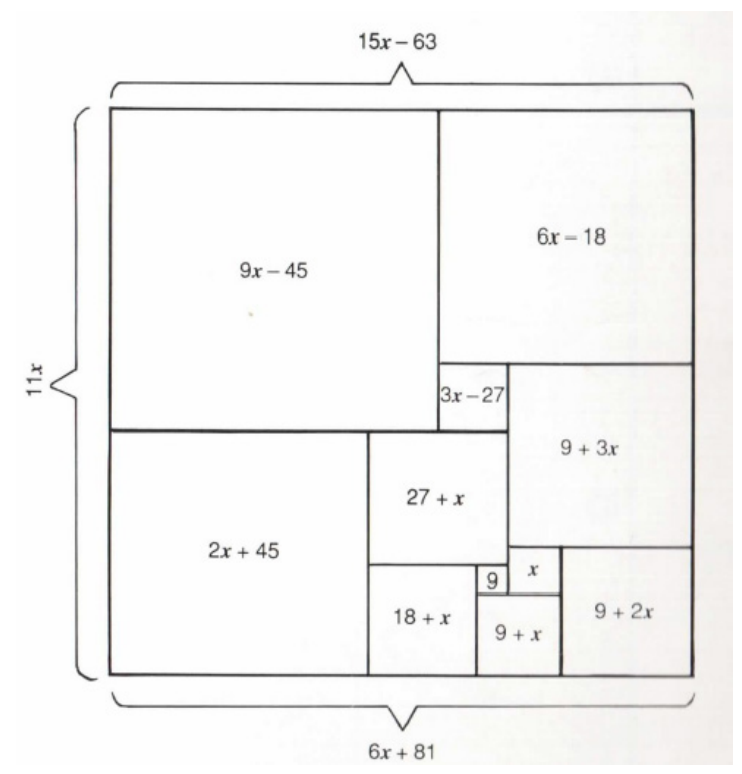

Figura 3 - Resposta para o problema do quadrado
Outros problemas podem ser abordados pelo professor após os alunos encontrarem os lados dos quadrados e do retângulo em termos da variável . O professor poderá, ainda, pedir que os alunos determinem o valor da variável, as áreas de cada um dos quadrados internos, do retângulo externo, os perímetros de cada figura, etc.

\section{Problema 4- Grandezas e Medidas}

Pedro comprou um aquário e colocou um peixinho dentro dele.

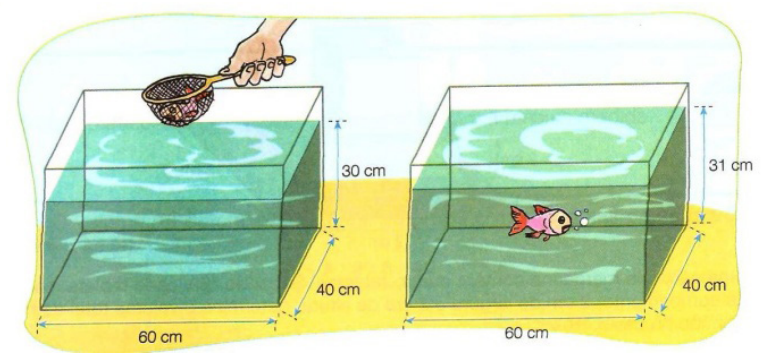

Figura 4 - Representação da situação problema

O menino ficou se perguntando:

a) Qual é o volume desse aquário?

b) Quantos litros de água esse aquário comporta?

c) Quanta água esse peixe deslocou?

d) Qual é o volume do peixinho?

Este problema é recomendado para alunos do $6^{\circ}$ ano do Ensino Fundamental, podendo ser expandido até o Ensino Médio, quando se trabalha Geometria Espacial.

Fazendo uso da Metodologia de Ensino-Aprendizagem-Avaliação de Matemática através da Resolução de Problemas, o professor deve entregar aos alunos uma folha com o problema, solicitar-lhes que façam a leitura e dividi-los em grupos.

Com este problema pretende-se explorar, principalmente, a relação entre o volume de 1 e a capacidade de .

O professor poderá retomar, se preciso para a resolução deste problema, alguns conhecimentos prévios do aluno, como o calculo do volume. Para isso, sugerimos algumas perguntas: "Como vocês calculariam o volume desse aquário?", "Como relacionamos o volume de um cubo à capacidade de um litro?".

Em grupos, os alunos deverão trabalhar sobre o problema e chegar a um consenso sobre a resposta Em seguida, o professor deve eleger um representante de cada grupo para colocar na lousa e expor à classe a resolução do seu grupo.

De acordo com as observações já realizadas em experimento anteriores, no item $a$ é comum que os alunos façam:

$$
V=60 \mathrm{~cm} .40 \mathrm{~cm} .30 \mathrm{~cm}=72000 \mathrm{~cm}^{3}
$$


No entanto, cabe ao professor destacar que não seria possível, pelos dados do enunciado, calcular o volume do aquário. Apenas conseguiríamos calcular o volume da parte do aquário que está preenchida pela água. Seria possível ainda colocar mais uma quantidade de água no aquário até que ele ficasse cheio até a borda.

O professor pode lembrar os alunos que o volume de $1 \mathrm{dm}^{3}=1000 \mathrm{~cm}^{3}$ comporta a capacidade de 1 litro. Sendo assim $72000 \mathrm{~cm}^{3}$, o volume de comportaria $72 l$ de água, o que responde ao item $b$.

No item $c$, o aluno, ao observar as figuras antes e depois de se colocar o peixinho, deverá perceber que o nível da água aumentou $1 \mathrm{~cm}^{3}$. O volume da parte do aquário que está preenchida por água e contém o peixinho é de:

$$
\mathrm{V}=60 \mathrm{~cm} \cdot 40 \mathrm{~cm} \cdot 31 \mathrm{~cm}=74400 \mathrm{~cm}^{3}
$$

Sendo assim, se, inicialmente, o aquário apresentava um volume de $72000 \mathrm{~cm}^{3}$ e depois, com o peixinho, passou a ser de $74400 \mathrm{~cm}^{3}$, ele deslocou $2400 \mathrm{~cm}^{3}$ que corresponde a $2,4 l$.

Respondendo ao item $d$, os alunos deveriam afirmar que o volume do peixinho é de $2400 \mathrm{~cm}^{3}$

O problema possibilita que o professor explore com alunos do Ensino Médio como determinar a massa do peixinho. Para isso, eles deveriam buscar auxílio na Física.

A plenária ao se trabalhar este problema se mostrará um momento bastante rico. O professor deverá conduzir os alunos para que essas discussões sejam encaminhadas em direção à construção dessas relações entre as unidades de medida de volume e de capacidade.

\section{Problema 5- Tratamento da Informação}

Os salários pagos a 8 funcionários de uma empresa são: $R \$ 500,00, R \$ 600,00, R \$ 600,00, R \$ 600,00, R \$ 800,00$, $R \$ 810,00, R \$ 810,00, R \$ 9.000,00$. Qual seria o salário mais provável de um funcionário que viesse a ocupar o cargo de um dos funcionários dessa empresa, se um dos cargos ficasse vago?

Os PCN recomendam que os conceitos de Média aritmética, de Moda e de Mediana sejam explorados a partir do quarto ciclo do Ensino Fundamental. Este problema tem por objetivo explorar esses conceitos com os alunos, bem como discutir a utilidade e limitação de cada um das medidas de tendência central.

Seguindo o roteiro da Metodologia de Ensino-Aprendizagem-Avaliação de Matemática através da Resolução de Problemas, o professor deverá entregar o problema aos alunos e solicitar-lhes que façam a leitura. Em seguida, o professor deverá dividir a turma em grupos.

Como mediador entre o aluno e a construção de seu conhecimento, o professor poderá lançar algumas perguntas aos grupos, visando a compreensão do problema e de sua solução: "Quantos funcionários recebem $R \$ 500,00$ ?" e R\$600,00?"e $R \$ 810,00$ ?" e $R \$ 9.000,00$ ?",
"Qual seria a média salarial dessa empresa?".

Ao calcular a média aritmética, eles obteriam:

$\frac{500+600+600+600+800+810+810+9000}{8}=R \$ 1652,5$

O professor deverá questionar os alunos se faz sentido, nesse caso, calcular a média aritmética. Eles deverão perceber que essa medida de tendência central não é apropriada para este problema.

O uso da mediana também não corroborou em nada, visto que o valor obtido, $\mathrm{R} \$ 700,00$ não representa nenhum dos salários pagos na empresa.

A moda, fator que mais se repete no conjunto de dados, mostra-se mais representativa para este problema. Como três funcionários recebem, por seus cargos, $\mathrm{R} \$ 600,00$, é mais provável que esse fosse o salário de um novo funcionário.

Após a plenária, o professor deverá formalizar os conceitos de média aritmética, moda e mediana. É importante que ele explique por que elas são chamadas de medidas de tendência central e trabalhe com problemas que permitam que o aluno perceba quando o uso de uma delas é mais adequado do que outra.

No final da aula, deverão concluir que:

- "A média é uma medida de tendência central muito afetada por valores extremos" (SÃO PAULO, 2009, p. 41).

- “Uma das desvantagens da mediana é a seguinte: se um dos dados do centro muda ligeiramente, a mediana pode alterar significativamente, o que já não acontece com a média, que relativamente é pouco afetada por uma pequena mudança nos números centrais" (SÃO PAULO, 2009, p. 43).

A moda, para este problema, foi a medida de tendência central cujo valor foi o mais significativo para representar o possível salário de um novo funcionário. Além da discussão do valor provável do salário do novo funcionário, o problema possibilita, ainda, a discussão com os alunos a respeito das diferenças salariais entre os funcionários, a probabilidade do novo funcionário se encaixar em um cargo de mais alto ou baixo salário, etc.

\section{Considerações Finais}

Ao trabalhar com a Metodologia de Ensino -Aprendizagem-Avaliação de Matemática através da Resolução de Problemas, utilizando o roteiro proposto por Onuchic e Allevato (2011), estamos salientando a necessidade de mudança no comportamento do professor - como mediador e facilitador; e foco no aluno - como parte principal e efetiva do processo de ensino-aprendizagem. 
Outra característica dessa Metodologia é a mudança na estrutura da aula que passa a ser mais abrangente, sendo possível discutir diversos conceitos e conteúdos em apenas um problema. Conforme experiências realizadas tanto com professores, como com alunos da Educação Básica e do Ensino Superior, no GTERP, observa-se que ao resolverem os problemas propostos, os alunos utilizam de várias e distintas abordagens a fim de buscar soluções, suscitando discussões e tornando assim o ambiente propício para alunos e professores, fazendo parte não apenas da formação matemática necessária como também auxiliando na formação do cidadão, ensinando-o a trabalhar em grupos.

Para isso, é importante que o professor trabalhe com seus alunos de forma cooperativa e colaborativa, aproveitando o momento da Plenária para ouvir e discutir técnicas, conceitos e procedimentos e, a partir deles, fazer a formalização dos conteúdos matemáticos estudados naquela aula.

Em relação aos blocos de conteúdo dos Parâmetros Curriculares Nacionais, apesar de alguns estados brasileiros possuírem suas próprias propostas curriculares, todas elas contemplam ou deveriam contemplar as orientações nacionais.

Destacamos, ainda, que o papel do professor é fundamental e de grande responsabilidade. Ele é quem deverá selecionar um problema adequado aos seus alunos para que possibilite a construção do conhecimento por parte deles.

Assim, nesse artigo, pretendíamos indicar um caminho, através da Resolução de Problemas aos professores, a fim de contribuir com os processos de ensino, aprendizagem e avaliação da Matemática e com a sua prática docente.

\section{Referências}

BRASIL, Ministério da Educação. Secretaria de Educação Média e Tecnológica. Parâmetros curriculares nacionais para o ensino médio. Brasília: MEC, 2000.

. Ministério da Educação. Secretaria da Educação Fundamental. Parâmetros Curriculares Nacionais: Matemática. Ensino de $5^{\circ}$ a $8^{\circ}$ séries. Brasília-DF: MEC, 1998.

Ministério da Educação. Lei de Diretrizes e Bases da Educação Nacional n. 9394, de 20 de Dezembro de 1996 Estabelece as diretrizes e bases da educação nacional. Brasília: MEC, 1997.

JUSTULIN, A. M. A Resolução de Problemas no contexto da Formação de Professores. Rio Claro, 2014. 245f. Tese (Doutorado em Educação Matemática)- Instituto de Geociências e Ciências Exatas, Universidade Estadual Paulista, Rio Claro, 2014.
KRULICK, S.; RUDNICK, J.A. Problem-Driven Math: Applying the Mathematics Beyond Solutions. Estados Unidos: Wright Group/McGraw-Hill, 2005.

NATIONAL COUNCIL OF TEACHERS OF MATHEMATICS. Mathematics Teacher. Calendar Problems. Reston: NCTM, 1993, v.86, no 8.

NOGUTI, F. C. H. Um Curso de Matemática Básica através da Resolução de Problemas para alunos ingressantes da Universidade Federal do Pampa - Campus Alegrete. Rio Claro, 2014. 370f. Tese (Doutorado em Educação Matemática)- Instituto de Geociências e Ciências Exatas, Universidade Estadual Paulista, Rio Claro, 2014.

NUNES, C. B. O Processo Ensino-AprendizagemAvaliação de Geometria através da Resolução de Problemas: perspectivas didático-matemáticas na formação inicial de professores de matemática. Rio Claro, 2010. 430f. Tese (Doutorado em Educação Matemática)- Instituto de Geociências e Ciências Exatas, Universidade Estadual Paulista, Rio Claro, 2010.

ONUCHIC, L. R. Ensino-aprendizagem de Matemática através da resolução de problemas. In: BICUDO, M. A. V.(Org.). Pesquisa em Educação Matemática: Concepções e Perspectivas. São Paulo: Editora UNESP, 1999. cap.12, p.199-220.

ONUCHIC, L. R.; ALLEVATO, N. S. G. Pesquisa em Resolução de Problemas: caminhos, avanços e novas perspectivas. In: Bolema, n. 41, v.25, p.73 - 98, 2011.

ONUCHIC, L. R.; ALLEVATO, N. S. G.; NOGUTI, F. C. H.; JUSTULIN, A. M. (Org). Resolução de Problemas: Teoria e Prática. São Paulo: Paco Editora, 2014.

POLYA, G. A arte de Resolver Problemas. 1945. Título em inglês: "How to solve it: a new aspect of mathematical method". Tradução de Heitor Lisboa Araújo. Rio de Janeiro: Interciência, 1995.

SÃO PAULO (Estado). Secretaria da Educação. Caderno do Professor: Matemática, Ensino Fundamental - $5^{\text {a }}$ série. Volumes 1 a 4. Coordenação geral de Maria Inês Fini. São Paulo: SEE, 2009. 